\title{
RANCANG BANGUN WEB E-LEARNING UNTUK PENGELOLAAN MATA PELAJARAN TIK PADA SMPIT ADZKIA SUKABUMI
}

\author{
Ramdhan Saepul Rohman ${ }^{1}$, Erni Ermawati ${ }^{2}$, Yusti Farlina ${ }^{3}$, Rifa Nurafifah Syabaniah ${ }^{4}$ \\ ${ }^{1}$ AMIK BSI Sukabumi \\ e-mail: ramdhan.rpe@bsi.ac.id \\ ${ }^{2}$ AMIK BSI Sukabumi \\ e-mail: erniermawati339@gmail.com
}

${ }^{3}$ AMIK BSI Sukabumi

e-mail: yusti.yfa@bsi.ac.id

${ }^{4}$ AMIK BSI Tasikmalaya

e-mail: rifa.rrf@bsi.ac.id

\begin{abstract}
Abstrak
Sekolah merupakan dunia pendidikan yang syarat akan kegiatan belajar mengajar. Banyak cara yang dapat dilakukan untuk kegiatan belajar mengajar ini, mulai dari cara yang paling mudah sampai dengan cara yang cukup sulit untuk dilakukan. E-learning ini sendiri merupakan alternatif yang dapat mempermudah kegiatan belajar mengajar antar guru dan siswa tanpa harus bertatap muka antara keduanya. Itulah kenapa kegiatan ini dikatakan sebagai kegiatan yang mudah dan dapat dilakukan dimanapun dan kapanpun. Pada setiap kegiatan belajar di sekolah selalu diselingi dengan adanya ujian. Maka dari itu, demi terlaksananya ujian dengan lancar dan agar siswa tidak salah dalam menjawab soal, maka dibuatlah soal latihan serta ulasan materi yang ditampikan dalam sebuah halaman web. Hal ini bertujuan untuk menguji kemampuan siswa dan juga sebagai acuan bagi siswa dalam menjawab soal-soal ujian yang mungkin tidak jauh berbeda dengan soal latihan serta materi dari matapelajaran yang diberikan. Disamping guru dan siswa dapat melakukan aktivitas masing-masing, mereka juga dapat saling berkomunikasi antara satu sama lain melalui forum diskusi yang telah disediakan ketika siswa mengalami kesulitan dalam mengakses web.
\end{abstract}

Kata Kunci : E-Learning, Sekolah, Siswa, Website

\begin{abstract}
School is the world of education that the requirement of teaching and learning activities. Many ways can be done for this learning activity, ranging from the easiest way to the way that is quite difficult to do. E-learning itself is an alternative that can facilitate teaching and learning activities between teachers and students without having face to face between the two. That's why this activity is said to be an easy activity and can be done anywhere and anytime. In every learning activity in school is always interspersed with the test. Therefore, for the implementation of the exam smoothly and so that students are not wrong in answering the matter, then made a matter of exercise and material reviews are displayed in a web page. It aims to test the ability of students and also as a reference for students in answering test questions that may not be much different from the exercise questions and materials from the given lesson. In addition to teachers and students can do their respective activities, they can also communicate with each other through discussion forums that have been provided when students have difficulty in accessing the web.
\end{abstract}

Keywords: E-Learning, School, Studen, Website 


\section{Pendahuluan}

Sekolah merupakan dunia pendidikan yang syarat akan kegiatan belajar mengajar. Banyak cara yang dapat dilakukan untuk kegiatan belajar mengajar ini, mulai dari cara yang paling mudah sampai dengan cara yang cukup sulit untuk dilakukan.

Pada masa sekarang ini, belajar tidak hanya dapat dilakukan di dalam kelas saja, namun juga dapat dilakukan dimanapun dan kapanpun atau yang biasa dikenal dengan istilah E-Learning.

E-learning merupakan revolusi yang berbasiskan pada teknologi internet dan bergelut di bidang pendidikan education). E-learning dapat dipakai agar dapat efeti pada seluruh proses pembelajaran (Diah \& Fadhillah, 2015)

Pada setiap kegiatan belajar di sekolah selalu diselingi dengan adanya ujian. Maka dari itu, demi terlaksananya ujian dengan lancar dan agar siswa tidak salah dalam menjawab soal, maka dibuatlah soal latihan serta ulasan materi yang ditampikan dalam sebuah halaman web. Hal ini bertujuan untuk menguji kemampuan siswa dan juga sebagai acuan bagi siswa dalam menjawab soal-soal ujian yang mungkin tidak jauh berbeda dengan soal latihan serta materi dari matapelajaran yang diberikan.

\section{Metode Penelitian}

Metode penelitian dan teknik pengumpulan data yang digunakan dalam penulisan penelitian ini adalah:

A. Metode Pengembangan Perangkat Lunak

Metode yang digunakan dalam pengembangan perangkat lunak ini sendiri menggunakan model waterfall (Ladjamudin, 2006:16) yang terbagi menjadi lima tahapan, yaitu :

1) Penentuan dan analisa spesifikasi

Langkah ini sendiri merupakan analisa terhadap kebutuhan sistem yang hendak dibuat, yakni sistem e-elarning. Pengumpulan data pada tahap ini dapat dilakukan dengan cara penelitian, wawancara maupun study literature. Tahapan seperti ini dapat menghasilkan beberapa data yang berhubungan dengan keinginan user terhadap sistem yang hendak dibangun.
2) Desain sistem dan perangkat lunak Pada tahap ini sendiri dilakukan pembuatan kerangka sistem yang akan dibangun sesuai dengan data yang telah diperoleh sebelum pembuatan sistem yang sebenarnya.

3) Implementasi dan ujicoba unit

Tahapan inilah yang merupakan tahapan nyata dalam mengerjakan suatu sistem. Hal ini berarti bahwa sistem yang sebenarnya telah siap untuk dibuat sesaat setelah dilakukannya pembuatan kerangka sistem.

4) Integrasi dan uji coba sistem

Tahapan ini dapat dikatakan sebagai tahapan terakhir dalam pembuatan sebuah sistem. Setelah melakukan analisa, design dan pengkodean maka sistem yang sudah jadi akan digunakan oleh user.

5) Operasi dan Pemeliharaan

Perangkat lunak yang sudah disampaikan kepada user pasti akan mengalami perubahan. perubahan tersebut bisa karena mengalami kesalahan karena perangkat lunak harus menyesuaikan dengan lingkungan.

B. Metode Pengumpulan Data

a. Observasi

Agar Website yang dirancang dapat sesuai dengan kondisi sekolah dan tentunya dapat dieksekusi sesuai dengan harapan, maka dari itu perlu dilakukan obrservasi atau penelitian pada sekolah terkait guna memproleh informasi yang relevan sesuai dengan kondisi sekolah tersebut.

b. Wawancara

Mengingat betapa pentingnnya kecocokan informasi antara topik yang diangkat dalam pembuatan Tugas akhir dengan objek yang dituju, maka dari itu disamping melakukan obrsevasi, perlu juga dilakukan wawancara pada pihak terkait yang merupakan guru (kesiswaan) di sekolah tersebut.

c. Studi Pustaka

Demi Mendukung informasi yang hendak disajikan pada setiap halaman website, perlu juga dilakukan pengumpulan data dari berbagai macam sumber, baik itu buku maupun internet. 
C. Ruang lingkup

Batasan untuk masalah yang hendak dibahas, hanya mencakup aktivitas siswa dan guru SMPIT Adzkia dalam Memanipulasi soal latihan dan ulasan materi dari setiap matapelajaran tertentu. Guru dapat mengganti dan memanipulasi soal sesuai dengan ketentuan, sedangkan siswa dapat mengerjakan soal serta mempelajari ulasan materi yang telah disediakan oleh guru dalam sebuah halaman web. Perlu diketahui bahwa setiap guru dan siswa, mempunyai hak akses masingmasing. Sedangkan, pihak administrasi web, dapat mengontrol siapa saja yang telah mengakses web. Hasil akhir (output) yang akan peroleh oleh siswa sesaat setelah mengerjakan soal dari matapelajaran tertentu yaitu berupa laporan tentang perhitungan nilai akhir dari jumlah banyaknya soal yang telah dijawab, baik itu benar maupun salah.

\section{Hasil dan Pembahasan \\ 3.1 Analisa Kebutuhan}

Dalam sistem e-learning ini sendiri terdapat berbagai macam informasi tentang mata pelajaran yang harus diikuti oleh setiap siswa. Mata pelajaran tersebut yaitu TIK (Teknologi Informasi dan Komputer). Informasi yang disajikan terkait mata pelajaran tersebut yaitu berupa bahan ajar (materi pembelajaran), latihan soal serta juga didukung dengan adanya forum diskusi yang memungkinkan siswa dapat saling berinteraksi dengan guru terkait, apabila siswa mengalami kendala. Dalam sistem ini, sudah jelas bahwa pelaku yang terlibat hanya melibatkan komponen sekolah saja yakni guru dan murid.

Untuk dapat mengakses website elearning ini sendiri, siswa harus mendaftar terlebih dahulu pada form pendaftaran agar identitas siswa dapat masuk ke database dan juga agar siswa dapat memiliki akun (username dan password). Akun tersebut nantinya dapat digunakan oleh siswa untuk login ke halaman e-learning. Pada saat login, siswa cukup memasukan e-mail mereka masing-masing pada bagian textbox username dan password pada bagian textbox password. Setelah itu, jika login berhasil siswa dapat melakukan beberapa aktivitas e-learning yang disajikan, seperti membaca materi pembelajaran, mengerjakan soal latihan (kisi-kisi ulangan/ujian) yang nantinya setiap hasil jawaban siswa akan ditampilkan serta juga siswa dapat bertanya pada guru melalui forum diskusi, jika diperlukan.

Disamping itu, guru juga melakukan aktivitas mengajar bagi siswa. Adapun beberapa hal yang dilakukan oleh guru diantaranya mengupdate soal, mengubah soal, menjawab pertanyaan siswa dan bahkan guru dapat melihat siapa saja siswa yang sedang atau telah masuk ke halaman e-learning.

Disediakan pula halaman admin untuk mengelola dan mengawasi setiap tindakan user. Sebelum masuk ke halaman admin, maka admin harus login terlebih dahulu. Pada halaman ini admin memiliki hak penuh untuk mengelola, mengubah, menghapus atau menambahkan beberapa informasi yang diperlukan.

\subsection{Database}

A. Entity Relational Diagram (ERD)

Pengertian ERD Menurut Jogiyanto (2005:700) "Adalah suatu komponenkomponen himpunan entitas dan himpunan relasi yang masing-masing dilengkapi dengan atribut yang mempresentasikan seluruh fakta dari dunia nyata yang ditinjau".

Terdapat Beberapa kompunen ERD yang sering digunakan dalam menggambarkan alur dari suatu sistem.

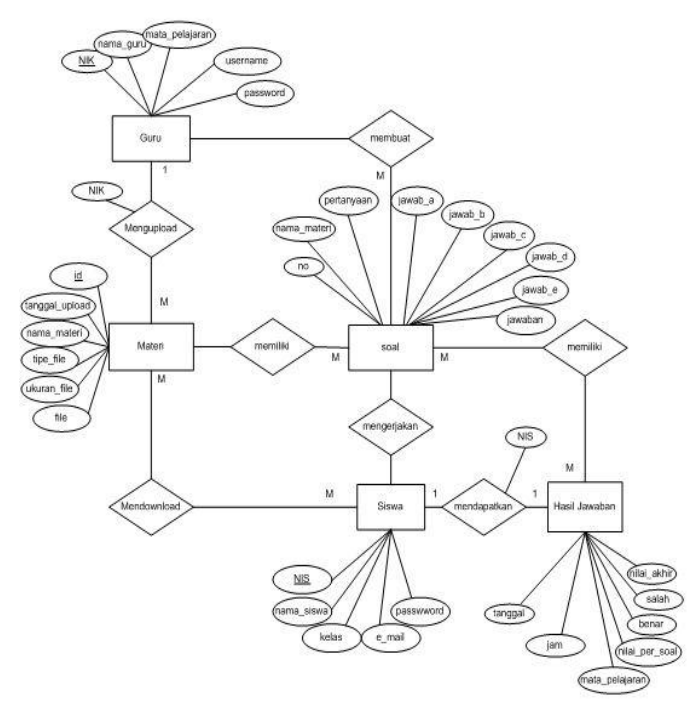

Gambar 1. Entity Relational Diagram 
B. Logical Relation Diagram

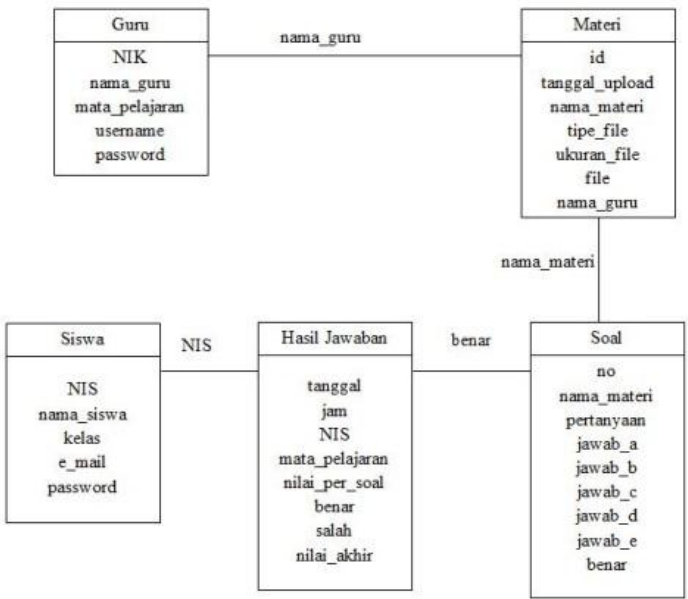

Gambar 2. Logical Relation Diagram

\subsection{Rancangan Struktur Navigasi}

Menurut Prihatna (2005:51) "Struktur Navigasi adalah susunan menu atau hirarki dari suatu situs yang menggambarkan isi dari setiap halaman dan link atau navigasi halaman pada suatu situs web".

Struktur navigasi website digunakan untuk menggambarkan secara garis besar isi dari seluruh web juga berfungsi untuk menggambarkan bagaimana hubungan antara setiap halaman pada web. Struktur navigasi website perancangan web $e$ elearning di SMPIT Adzkia ini menggunakan struktur navigasi hirarki (Hierarchy) untuk halaman portal (front end) dan composite (campuran) untuk halaman admin (back end). Dengan menggunakan struktur navigasi ini, akan terlihat bagaimana isi dari sebuah website secara keseluruhan.

A. Rancangan struktur navigasi portal web front end

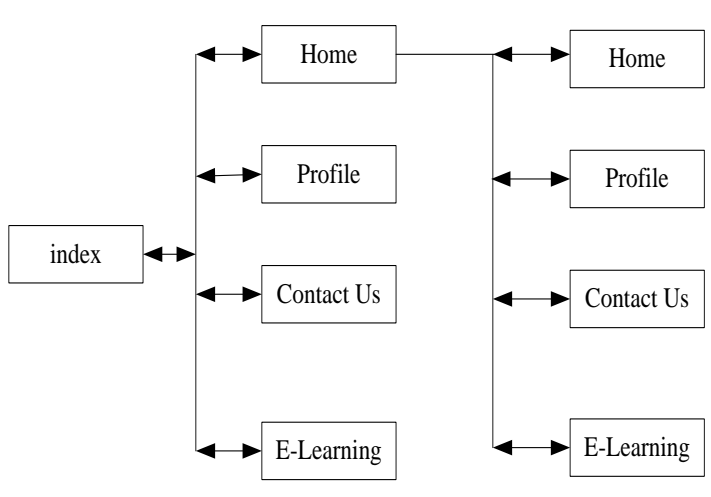

Gambar 3. Struktur Navigasi Web Front End

B. Rancangan struktur navigasi web back end

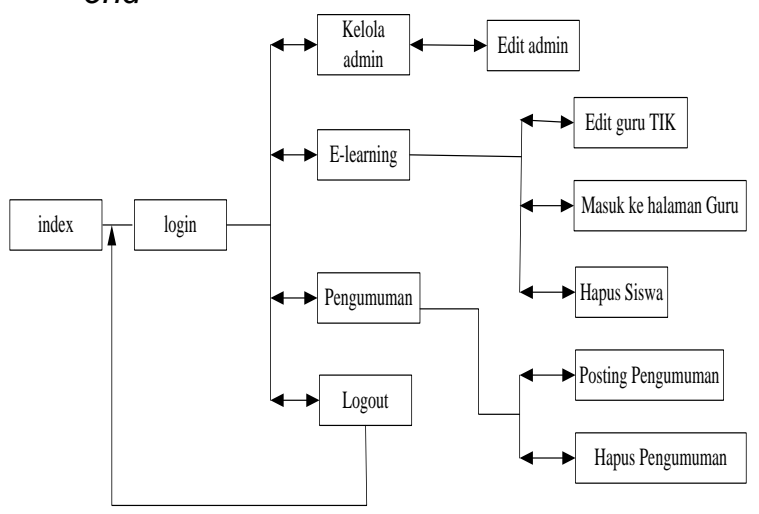

Gambar 4. Struktur Navigasi Web Back
End

\subsection{User Interface}

\section{A. Halaman Utama Website}

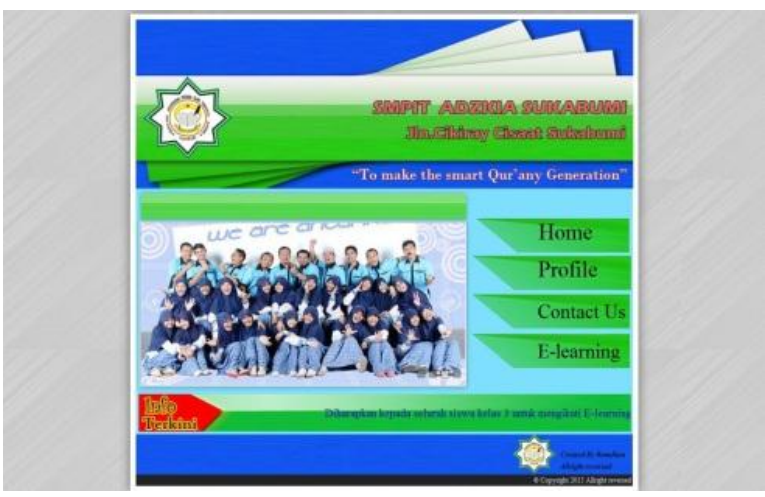

Gambar 5. Implemetasi Halaman Utama

B. Implementasi Halaman Admin 


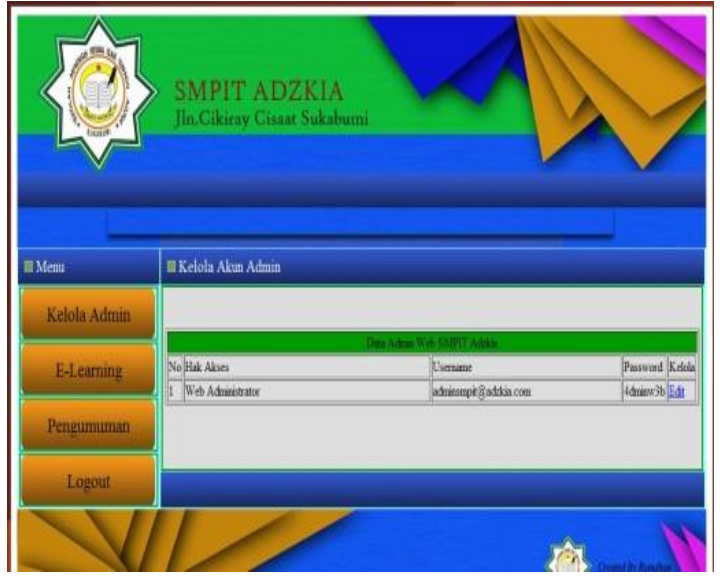

Gambar 6. Implementasi Halaman Admin

C. Halaman Portal E- Elearning

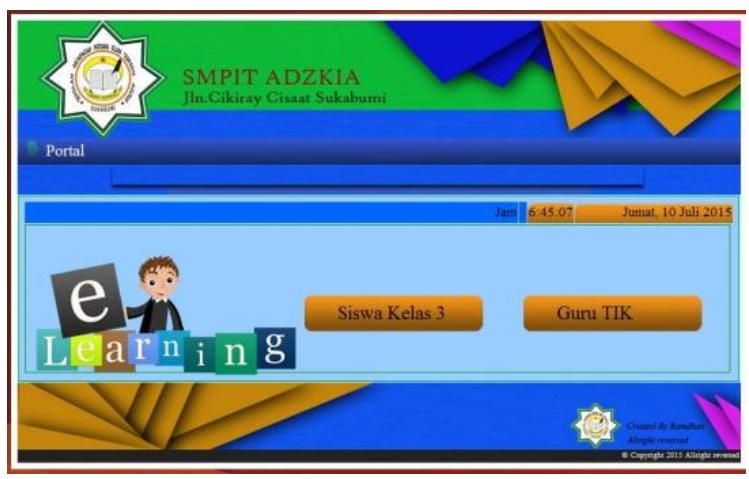

Gambar 7. Implementasi Halaman portal E-learning

D. Implementasi halaman login siswa

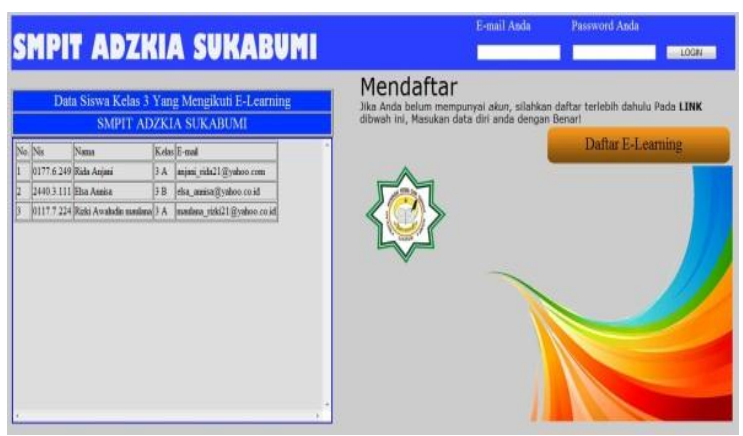

Gambar 8. Implementasi Halaman login siswa

E. Implementasi Halaman User

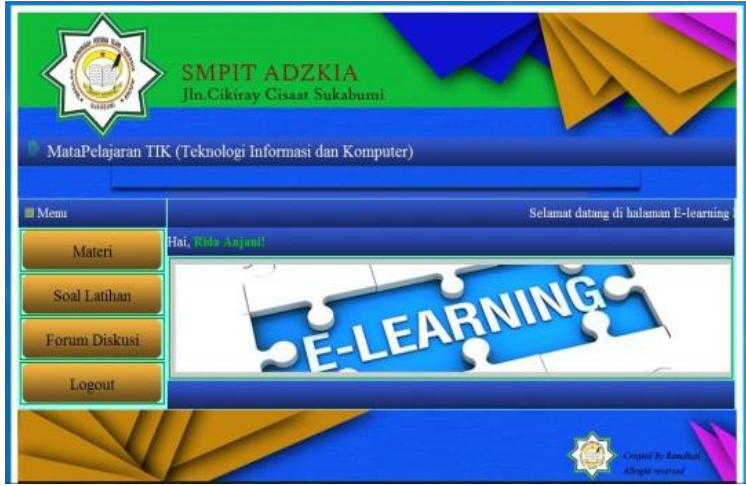

Gambar 9. Implementasi Halaman User

\section{F. Implementasi Halaman Ujian}

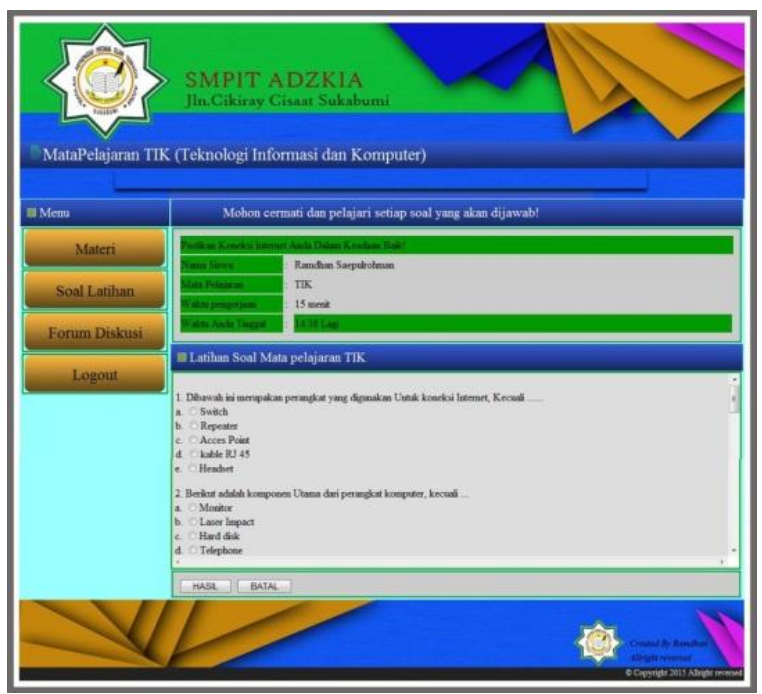

Gambar 10. Implementasi Halaman Ujian

G. Implementasi kelola materi untuk guru 


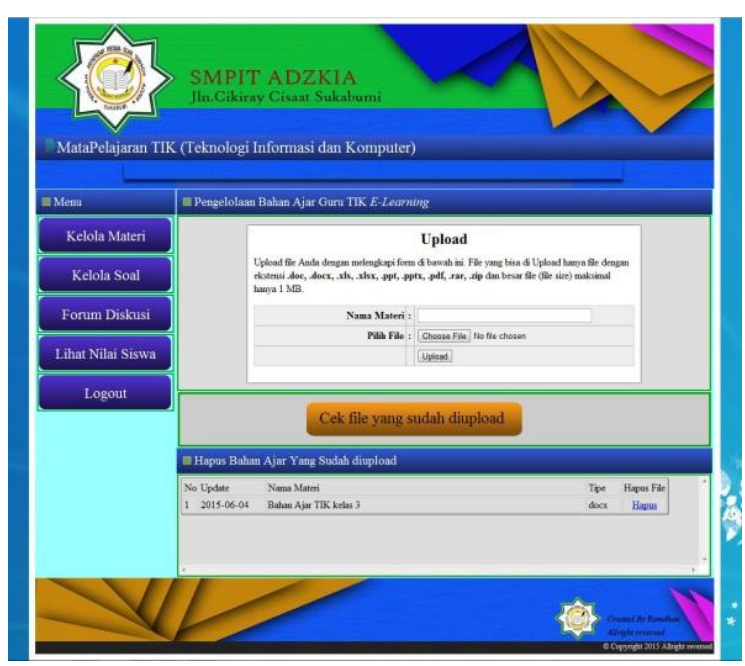

\section{Gambar 11. Implementasi Kelola materi untuk guru}

\section{Kesimpulan}

Kemajuan suatu sekolah tentunya banyak dipengaruhi oleh berbagai macam faktor, salah satu diantaranya adalah faktor teknologi. Agar suatu sekolah dapat dikatakan up to date, maka tentulah harus menyesuaikan dengan perkembangan zaman. Maka dari itu, tidak ada salahnya jika sebagian kegiatan belajar mengajar dialihkan pada sistem digital yang biasa dikenal dengan istilah e-learning. Hal ini bertujuan agar komponen sekolah, baik itu guru maupun siswa dapat terbiasa dengan hal-hal yang bersifat digital. Disamping itu juga, kegiatan e-learning ini sendiri diharapkan dapat memajukan sekolah yang bersangkutan.

\section{Referensi}

Al-bahra, L. B. (2006). Rekayasa Perangkat Lunak. Yogyakarta: Graha Ilmu.

Diah, R. A., \& Fadhillah, U. (2015). Rancang Bangun Website dan ELearning. Surakarta: Khazanah Informatika.

Henky, P. (2015). Kiat Praktis Menjadi Webmaster Profesional. Jakarta: PT.Elex Media Komputindo.

Jayan. (2010). CSS untuk orang awam. Palembang: Maxikom.

Jogiyanto. (2005). Analisa Perancangan dan Desain. Yogyakarta: Andi.
Madcoms. (2012). Javascript untuk membangun website profesional. Yogyakarta: Andi.

Nugroho, B. (2009). Database relasional Dengan MySQL. Yogyakarta: Andi.

Saropi. (2008). Step by step CMS MAMBO. Jakarta: PT.Elex Media Komputindo.

Simarmata, J. (2010). Rekayasa Perangkat Lunak. Yogyakarta: Andi. 